\title{
Distribution extension of Oriental mayfly Clypeocaenis oligosetosa Soldán, 1983 (Ephemeroptera: Caenidae)
}

\begin{abstract}
Alexander V. Martynov ${ }^{1,3} \&$ Dmitry M. Palatov ${ }^{2}$
${ }^{1}$ National Museum of Natural History, National Academy of Sciences of Ukraine, Bohdan Khmelnitsky str., 15, 01601 Kiev, Ukraine ${ }^{2}$ Department of Hydrobiology, Biological Faculty, Moscow State University, Leninskie Gory 1/12, 119234 Moscow, Russian Federation ${ }^{3}$ Corresponding author. E-mail: martynov_av@ukr.net, centroptilum@gmail.com
\end{abstract}

\begin{abstract}
Clypeocaenis Soldán, 1978 consists of 7 species, 3 of them are known from the Oriental region. Clypeocaenis oligosetosa Soldán, 1983 was described from Vietnam and until now was known only from 2 localities within this country. We found C. oligosetosa in Thailand for the first time. This record significantly extends the known distribution of the species. The main distinguishing characters of the larvae of C. oligosetosa are illustrated. We observed a few small morphological differences between Thai specimens, investigated paratypes of $C$. oligosetosa and its original description.
\end{abstract}

Key words. New record; type material; Pannota; Clypeocaenini; Thailand; Vietnam; Oriental Region

Clypeocaenis Soldán, 1978 (Caenidae: Clypeocaenini) is a rare genus consisting of 7 species distributed in the Oriental, Palaearctic, and Afrotropical regions (Soldín 1978, 1983, Soldán \& LANDA 1991, Malzacher 2013, MalzaCher \& STANICHEK 2016). Three species of the genus are known from the Oriental region, and only one of them, Clypeocaenis oligosetosa Soldán, 1983 is distributed in the continental part of this region. The species was described from Thuan Hai Province in Vietnam (SoLDÁN 1983). Later it was found in Nam Cat Tien National Park (Vietnam) in 1989 (Soldén 1991). According to Soldín $(1983,1991)$ C. oligosetosa was abundant in both sampling places. There were no other records of this species until now. We found $C$. oligosetosa in Thailand for the first time, what extends its known distribution.

All material used in this investigation was preserved in 80-95\% EtOH; some larvae were mounted on slides with Canada balsam. The material on C. oligosetosa from Thailand is stored in the collection in the National Museum of Natural History of the National Academy of Sciences of Ukraine (the inventory number of vial is Thai8Clysp, number of slide is 638).

Original material. 2 larvae (one mounted in Canada balsam, slide no. 638) Thailand, Chiang Mai Province, Mae-Chaem

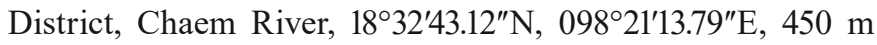
a.s.1., 21.xi.2009, Palatov D.M. \& Chertoprud M.V. leg.
Comparative material. Paratypes, 7 larvae (1 newly mounted in slide, no. 659) and 1 larval skin (newly mounted in slide, no. 660), Vietnam, Thuan Hai Province, Song Kinh-Dinh River, Nha-Ho, $15 \mathrm{~km}$ W of Phan Rang, $11^{\circ} 37^{\prime} 58^{\prime \prime} \mathrm{N}, 108^{\circ} 52^{\prime} 19^{\prime \prime} \mathrm{E}$, 16.iv-5.v.1982, T. Soldán leg.

The collected Thai specimens were identified as Clipeocaenis oligosetosa basing on the main distinguishing features of this species: shapes of labrum, maxillary palp and labial palp, setation of legs. These characters also distinguish $C$. oligosetosa from all other species of the genus.

The Thai specimens of $C$. oligosetosa almost fully correspond to the Vietnamese type specimens in the characters as illustrated in Figures 1-10. We observed one difference: specimens from the Chaem River had only 2 long hair-like setae on clypeal protrusion (Fig. 2) in contrast to larvae from the type locality with 4-6 (usually 4) long hair-like setae (SoLDÁN 1983, original data). Additionally, larvae from Thailand and examined type specimens appeared to have pedicellus distinctly broader than the first segment of flagellum (Fig. 2), in contrast to the illustration of SOLDÁN (1983: 198, fig. 4).

The first record of the genus Clypeocaenis from Thailand (Songkhla Province) was published by SITES et al. (2001), but as they only had immature larvae, the mayflies were only identified to genus (Fig. 11). They noted that the diagnostic character of the number of setae on the anterior margin of the clypeal protrusion showed intraspecific variation and suggested that a revision of the genus is required.

In Thailand, the larvae of C. oligosetosa were sampled from the Chaem River, Shan Highland (Fig. 12). The river here was $15-20 \mathrm{~m}$ wide, up to $1.5 \mathrm{~m}$ deep, the substrate was sand, pebble, silt, and detritus, and the current velocity was up to $1 \mathrm{~m} / \mathrm{s}$. Water temperature on the day of sampling was approximately $21{ }^{\circ} \mathrm{C}$. Numerous settlements and agricultural lands along the river defined a very noticeable level of pollution (beta-mezosaprobic) and increased turbidity. Larvae were collected from submerged grass, detritus, and Phragmites sp.

Thus, ecological preferences of $C$. oligosetosa in North Thailand and South Vietnam are quite similar. The larvae of this species inhabit large, well-warmed plain or lowland 

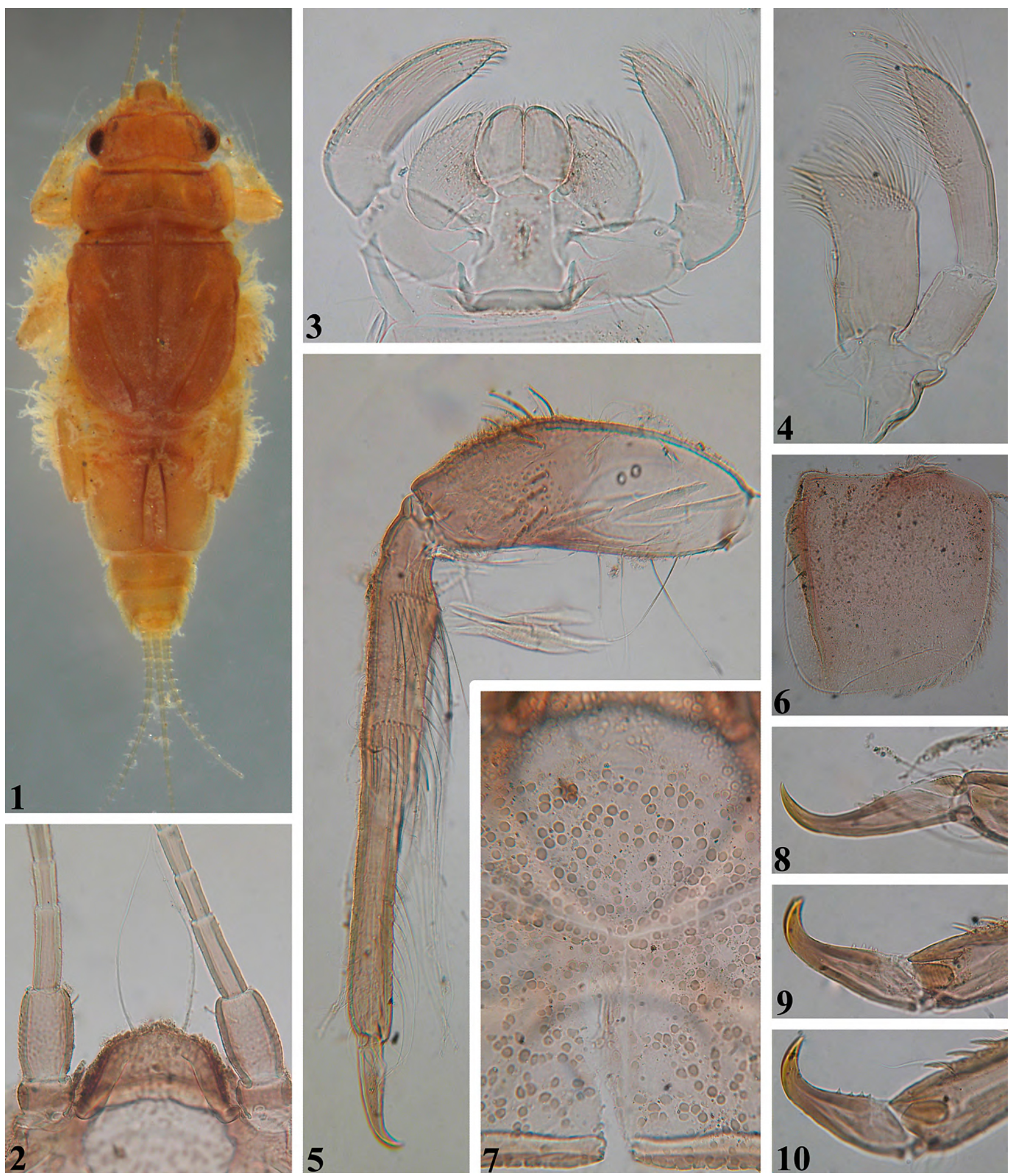

Figures 1-10. Larvae of Clypeocaenis oligosetosa Soldán, 1983 from the Chaem River, Thailand: 1. Total view of larva. 2. Clypeal protrusion and antennae. 3. Labium. 4. Maxilla. 5. Fore leg. 6. Gill II. 7. Surface of head near frontal suture. 8-10. Tarsal claws of fore, middle and hind legs.

watercourses with relatively low flow rates and significant siltation of bottom substrates. They occur in the subcoastal zone, where they inhabit roots of plants, small stones, and detritus. The species develops in quite a wide temperature range from $37.7^{\circ} \mathrm{C} / 22.7^{\circ} \mathrm{C}$ (day/night water temperature at the sampling place in South Vietnam, according to SoldÁn 1983) to $21^{\circ} \mathrm{C} / 18^{\circ} \mathrm{C}$ (day/night water temperature at the sampling place of collection in northern Thailand). In northern Thailand, C. oligosetosa was found together with other Pannota species-Dudgeodes romani Martynov, Palatov \& Boonsoong, 2016 (Teloganodidae), Teloganopsis jinghongensis (Xu, You \& Hsu, 1984) (Ephemerellidae), Potamanthellus edmundsi Bae \& McCafferty, 1998 (Neoephemeridae), and Brachycercus sp. (Caenidae) (MARTYNov et al. 2016, original data). 


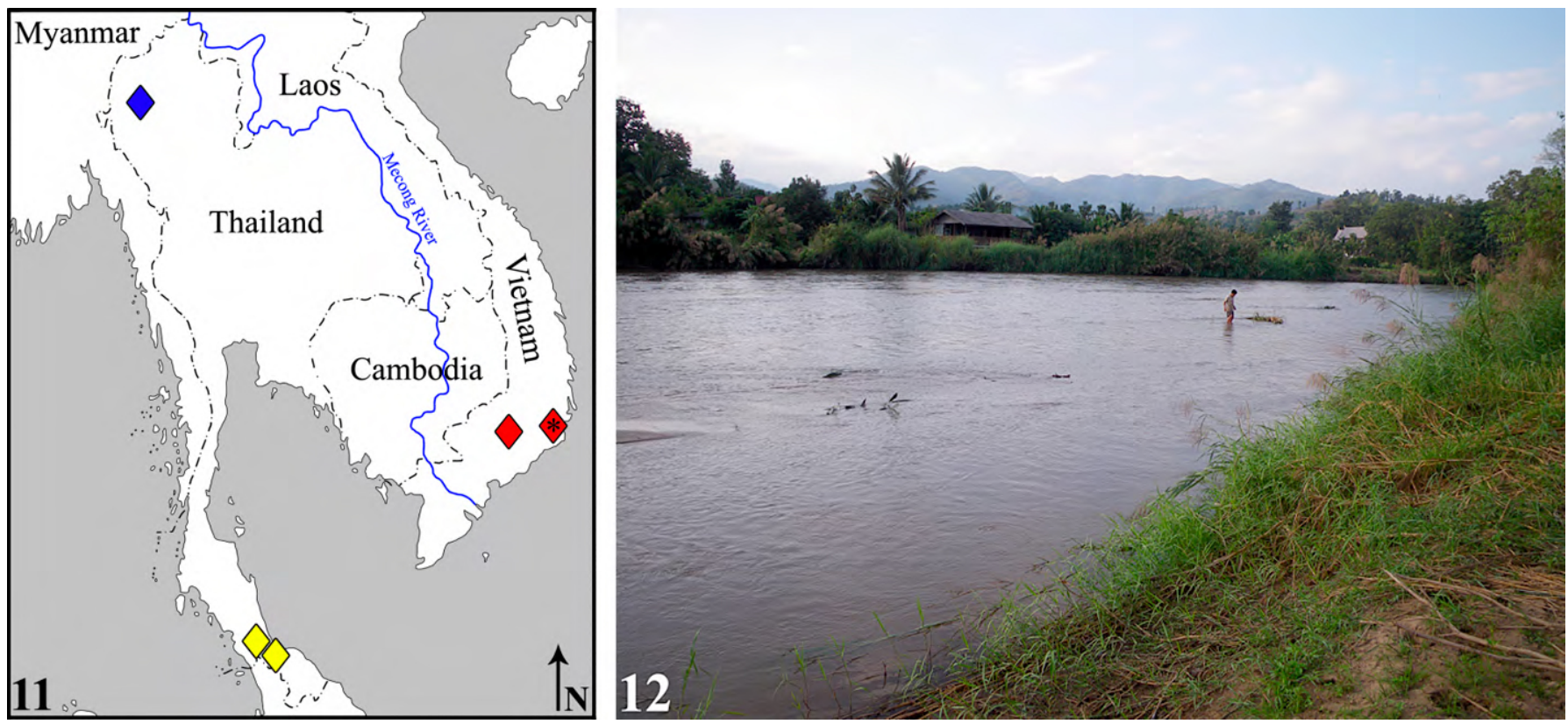

Figures 11-12. Collection sites of Clypeocaenis oligosetosa Soldán, 1983 and Clypeocaenis sp. in Thailand and Vietnam. 11. Sampling sites of Clypeocaenis oligosetosa and Clypeocaenis sp. in Thailand and Vietnam (blue diamond = new record of C. oligosetosa; red diamonds = records of $C$. oligosetosa in Vietnam (with asterisk = type locality); yellow diamonds = records of Clypeocaenis sp. by Sites et al. 2001). 12. Chaem River, site of new record of Clypeocaenis oligosetosa Soldán, 1983 in Thailand.

Our collection of $C$. oligosetosa in Thailand significantly expands the range of this species. This new record in Thailand is more than $1300 \mathrm{~km}$ northwest of the two previous records (Fig. 11). We predict that C. oligosetosa may inhabit similar waterbodies in Cambodia and Laos. It also might be found in adjacent regions of Shan Highland (including in Myanmar). Nevertheless, we did not find $C$. oligosetosa in the southern part of Cambodia during our investigation of the mayflies in this country in 2009 and 2015.

\section{ACKNOWLEDGEMENTS}

We are grateful to Dr. Tomáš Soldán (Institute of Entomology, Biology Centre, Czech Academy of Sciences, České Budějovice, Czech Republic) for putting the type material on C. oligosetosa at our disposal for comparison, and to Dr. M.V. Chertoprud (Moscow State University, Moscow, Russian Federation) for his help when collecting material in Thailand.

\section{LITERATURE CITED}

Malzacher, P. 2013. Caenidae from East Kalimantan, Borneo (Insecta: Ephemeroptera). With a discussion on phylogeny of the new tribe Clypeocaenini, subfamily Caeninae. Stuttgarter Beiträge zur Naturkunde A, Neue Serie 6: 21-55.

Malzacher, P. \& StaniczeK, A.H. 2016. Two new genera of Caeninae (Ephemeroptera: Caenidae), with a cladistic analysis of the tribe Clypeocaenini. Stuttgarter Beiträge zur Naturkunde A, Neue Serie 9: 41-62. https://doi.org/10.18476/sbna.v9.a4

Martynov, A.V., Palatov, D.M. \& Boonsoong, B. 2016. A new species of Dudgeodes Sartori, 2008 (Ephemeroptera: Teloganodidae) from Thailand. Zootaxa 4121: 545-554. https://doi.org/10.11646/ zootaxa.4121.5.4
Sites, R.W., Wang, T., Permkam, S. \& Hubbard, M.D. 2001. The mayfly genera (Ephemeroptera) of southern Thailand. Natural History Bulletin of the Siam Society 49: 243-268.

SoldÁn, T. \& LANDA, V. 1991. Two new species of Caenidae (Ephemeroptera) from Sri Lanka; pp. 235-246, in: AlbA-TerCEDOR, J. \& Sanchez-Ortega, A. (eds.). Overview and strategies of Ephemeroptera and Plecoptera (Proceedings of the 6th International Conference of Ephemeroptera \& 10th International Symposium on Plecoptera, 24-30 July 1989, Granada, Spain). Gainesville: Sandhill Crane Press.

SoldÁn, T. 1978. New genera and species of Caenidae (Ephemeroptera) from Iran, India and Australia. Acta Entomologica Bohemoslavaca 75(2): 119-129.

SoldÁn, T. 1983. Two new species of Clypocaenis (Ephemeroptera, Caenidae) with a description of adult stage and biology of the genus. Acta Entomologica Bohemoslovaca 80(3): 195-206.

SoldAN, T. 1991. An annotated list of mayflies (Ephemeroptera) found in the Nam Cat Tien National Park; pp. 4-9, in: Spitzer, K., Leps, J. \& Zahrada, M. (eds.). Nam Cat Tien, Czechoslovak Vietnamese Expedition, November 1989, Research Report. Institute of Entomology of Czechoslovak Academy of Sciences, České Budějovice.

Authors' contributions. DMP collected the data, AVM identified the specimens and made the figures, AVM and DMP wrote the text.

Received: 7 February 2017

Accepted: 4 April 2017

Academic editor: Rodolfo Mariano 